\title{
Extraction of Plutonium Using DIPEX Immobilized in Polystyrene Thin Films
}

Hakim Boukhalfa ${ }^{1 *}$, Dominic S. Peterson ${ }^{2}$, Edward R. Gonzales $^{3 \dagger}$, Crystal L. TulleyCordova $^{3 \dagger}$, Sowmitri Tarimala ${ }^{1}$, and Stuart D. Ware ${ }^{1}$

${ }^{1}$ Earth and Environmental Sciences Division EES-14, Los Alamos National Laboratory, Los Alamos, NM 87545, USA

${ }^{2}$ Materials Sciences and Technologies Division MST-7, Los Alamos National Laboratory, Los Alamos, NM 87545, USA

${ }^{3}$ Chemical Diagnostics and Engendering Division, Los Alamos National Laboratory, Los Alamos, NM 87545, USA.

$\dagger$ Current affiliation: University of Utah, Department of Geology and Geophysics

* To whom Correspondence should be addressed.

hakim@lanl.gov Fax: 505-667-7219 


\begin{abstract}
We previously reported the development of thin films functionalized with P,P'-di(2ethylhexyl) methanediphosphonic acid (DIPEX) applied to the extraction and analysis (by alpha spectrometry) of actinide samples. Here we report the full characterization of the films' ability to extract $\mathrm{Pu}(\mathrm{III}), \mathrm{Pu}(\mathrm{IV}), \mathrm{Pu}(\mathrm{V}), \mathrm{Pu}(\mathrm{VI})$, and colloidal $\mathrm{Pu}(\mathrm{IV})$ under various chemical conditions. For all oxidation states, plutonium partitioning onto DIPEXpolystyrene thin films was less effective than that onto liquid DIPEX. The weight distribution ratios calculated for the thin film extraction efficiency for the different oxidation states were $\mathrm{Pu}(\mathrm{IV})>\mathrm{Pu}(\mathrm{III})>\mathrm{Pu}(\mathrm{VI}) \cong \mathrm{Pu}(\mathrm{V}) \cong$ colloidal $\mathrm{Pu}(\mathrm{IV})$ and were more than $10^{3}$ times lower than the distribution ratios observed for liquid DIPEX. Application of the DIPEX-polystyrene thin films for the qualitative processing of contaminated soil samples was very effective; however, the films were less effective for the processing of large water samples with trace levels of plutonium.
\end{abstract}

Keywords. Plutonium, DIPEX, extraction, alpha spectrometry, thin films 


\subsection{Introduction}

Detection of plutonium and other actinides in environmental samples is important for environmental monitoring, threat reduction, and nonproliferation efforts. The detection of plutonium in liquid effluents is particularly difficult because of the very low solubility of plutonium oxy(hydr)oxides that predominate under most environmental conditions and the tendency of plutonium species to strongly associate with environmental solids [1]. The soluble concentration of plutonium is limited by the solubility limit of plutonium oxides, which is approximately $10^{-10}$ to $10^{-12} \mathrm{M}$ depending on the set of thermodynamic data used [1,2]. However, analyses of environmental samples showed that plutonium concentrations in environmental samples varied significantly. The concentration of plutonium in sea water varies from femtograms to picograms per $\mathrm{kg}(0.002$ to 0.2 $\mathrm{mBq} / \mathrm{kg}$ ), and in liquid waste from reprocessing facilities, plutonium is present in picograms to micrograms per $\mathrm{kg}$. Plutonium is also present in sediments and contaminated soils at much higher levels near nuclear facilities and sites used for the reprocessing of nuclear materials [2-6]. Standard spectroscopic methods such as UVvisible and electrochemical techniques lack the sensitivity for the direct measurement of plutonium at these low environmental concentrations [2]. This prompted the development of sample processing, concentration, and analysis techniques that are better adapted to tracer levels. Using high affinity resins and ICP-MS, detection of plutonium in subfemtograms per $\mathrm{kg}$ is easily attainable [7-13]. However, these techniques often require the processing of large amounts of environmental samples to bring plutonium concentration to detectable levels; these techniques are time consuming and often require expensive laboratory equipment. 
In recent years, numerous approaches have been developed to enable the rapid separation and detection of actinides from environmental and biological samples that are more portable and can be adapted to field settings. These techniques involve sample dissolution, concentration, and extraction using high-affinity thin films and sample analysis by alpha spectrometry. Extraction of plutonium and other actinides is achieved using functionalized thin films that have a very high affinity for actinide adsorption [1417]. The thin films are functionalized by covalent incorporation of specific functional groups onto the polymer structure or the immobilization of ligands with high binding affinity for actinides in the rigid structures of inert polymers. Functional groups used include acetamide functional groups, amidoximes, phosphonic acid groups, hydroxamates, and carboxylic acid groups [18-25]. Extraction of actinides using pure mineral phases such as Muscovite was also tested for the rapid qualitative analysis of actinides in aqueous samples [26]. These films, when combined with alpha spectrometry, perform reasonably well and enable a very rapid qualitative analysis of the sample with very good peak resolution and low background interference. However, these thin films are less reliable for direct quantitative analyses and are often not very selective. They are selective only for specific oxidation states and require some sample processing to achieve reasonable extraction efficiency.

The current work presents an in-depth examination of plutonium extraction using polystyrene thin films with immobilized P,P'-di(2-ethylhexyl) methanediphosphonic acid (DIPEX), a ligand with a high affinity for the binding of actinides [27,28] (scheme 1). We examined the extraction of $\mathrm{Pu}(\mathrm{III}), \mathrm{Pu}(\mathrm{IV}), \mathrm{Pu}(\mathrm{V})$, and $\mathrm{Pu}(\mathrm{VI})$ species by DIPEX thin 
films under various chemical conditions. Suspensions of intrinsic colloidal $\mathrm{Pu}(\mathrm{IV})$ were also prepared and equilibrated with the functionalized thin films to determine their ability to extract colloidal plutonium. This study examines how changes in plutonium coordination chemistry affect its partitioning to functionalized thin films and explores the chemical processes that could be incorporated in sample processing to chemically transform and enhance plutonium extractability. Moreover, our results are compared with the extraction data from previous studies that used the ligand DIPEX in a liquid form and are discussed to illustrate the importance of ligand aggregation and flexibility in actinide extraction using diphosphonic acid ligands.

\subsection{Materials and Methods}

\subsection{Materials and instruments}

All solutions were prepared using deionized water. Nitric acid, ammonium hydroxide, and hydroxyl amine hydrochloride were obtained from Fisher Scientific. THF was obtained from ACROS Organics. All chemicals were used without any further purification. The ligand P,P'-di(2-ethylhexyl) methanediphosphonic acid (DIPEX®) was obtained from Eichrom and the Planchet from Alantic Nuclear Corp. Polystyrene was obtained from Sigma-Aldrich. The UV-visible spectra were collected using a Varian Cary $6000 \mathrm{i}$ spectrophotometer with a 0.20 -nm bandwidth. All the measurements were made using a $1.0-\mathrm{cm}$ quartz cuvette at $25{ }^{\circ} \mathrm{C} . \mathrm{Pu}(\mathrm{IV})$ colloids' size distribution was determined using a Zetasizer Nano (Malvern Instruments, Worcestershire, UK) equipped with a 633nm wavelength laser beam. A liquid scintillation counter (Packard Tri-Carb 2550 Liquid Scintillation Counter) was used to determine the radioactivity in solutions. 


\subsection{Preparation of DIPEX-polystyrene thin films}

All DIPEX-polystyrene thin films used in this study contained 1:10 DIPEX:Polystyrene (wt:wt). This ratio was selected because the most stable (durable) and effective thin films were formed at this ratio. Films with higher DIPEX content tend to be more brittle, especially when exposed to higher concentration of calcium. The solution mixtures used to make the thin films were prepared by dissolving the appropriate amounts of DIPEX and polystyrene in THF or toluene and homogenizing the solution by letting it sit overnight. The solutions typically contained $100 \mathrm{~mL}$ of solvent, $1.0 \mathrm{~g}$ of DIPEX, and 9.0 $\mathrm{g}$ of polystyrene. The thin films were prepared by transferring $1.5 \mathrm{~mL}$ of the diluted DIPEX:polystyrene solution to a 40-mm-diameter stainless steel planchet and allowing the solvent to slowly evaporate at room temperature for approximately $24 \mathrm{~h}$. This procedure usually produces consistent results and deposits on average $0.166 \pm .009 \mathrm{~g}$ of film on the planchet.

\subsection{Preparation of plutonium solutions with pure oxidation states}

Preparation and characterization of $\mathrm{Pu}(\mathrm{III})$ solutions. Pure $\mathrm{Pu}(\mathrm{III})$ solutions were prepared by the reduction of purified $\mathrm{Pu}(\mathrm{IV})$ solutions with zinc mercury amalgam. The solutions were assayed for purity and concentration in $1.0 \mathrm{M} \mathrm{HClO}_{4}$. $\mathrm{Pu}(\mathrm{III})$ solutions give a distinctive absorption band at $601 \mathrm{~nm}$ with an extinction coefficient of $38 \mathrm{M}^{-1} \mathrm{~cm}^{-}$

${ }^{1}$ (Figure S1 in supporting information) [29, 30]. Solutions of $\mathrm{Pu}(\mathrm{III})$ were relatively stable but slowly oxidized to $\mathrm{Pu}(\mathrm{IV})$, especially at near neutral $\mathrm{pH}$. 
Preparation and characterization of $\mathrm{Pu}(\mathrm{IV})$ solutions. $\mathrm{Pu}(\mathrm{IV})$ stock solution was prepared by the acid dissolution of plutonium metal. Plutonium metal was dissolved in chilled $6.0 \mathrm{M} \mathrm{HCl}$ to give a $\mathrm{Pu}(\mathrm{III})$ solution, which was mixed with an equal volume of 16.0 $\mathrm{M} \mathrm{HNO}_{3}$ and left to equilibrate overnight to give a pure $\mathrm{Pu}(\mathrm{IV})$ solution. Solutions of all other oxidation states were prepared from the same $\mathrm{Pu}(\mathrm{IV})$ stock solution. The concentration of $\mathrm{Pu}(\mathrm{IV})$ stock solutions was determined spectrophotometrically using the absorbance band at $470 \mathrm{~nm}$ and a molar absorptivity coefficient of $56 \mathrm{M}^{-1} \mathrm{~cm}^{-1}$ (Figure S1 in supporting information) [29].

Preparation and characterization of $\mathrm{Pu}(\mathrm{VI})$ solutions. Dilute $\mathrm{Pu}(\mathrm{VI})$ stock solutions were prepared by passing ozone through purified $\mathrm{Pu}(\mathrm{IV})$ solutions in $\mathrm{HCl}$ for several hours. The concentration and purity of the $\mathrm{Pu}(\mathrm{VI})$ stock solutions were assessed using Vis-NIR spectra of the solutions in $1.0 \mathrm{M} \mathrm{HClO}_{4}$. Pu(VI) gives an intense and distinctive absorbance band at $830.5 \mathrm{~nm}$, with an extinction coefficient of $555 \mathrm{M}^{-1} \mathrm{~cm}^{-1}$ [29]. The pure $\mathrm{Pu}(\mathrm{VI})$ is then diluted to the desired concentration in distilled water. The hexavalent oxidation state of plutonium in the dilute form reduces relatively rapidly to form $\mathrm{Pu}(\mathrm{V})$ and $\mathrm{Pu}(\mathrm{IV})$ and needs to be prepared fresh before each experiment.

Preparation and characterization of $\mathrm{Pu}(\mathrm{V})$ solutions. Dilute $\mathrm{Pu}(\mathrm{V})$ stock solutions were prepared from purified $\mathrm{Pu}(\mathrm{IV})$ by first oxidizing $\mathrm{Pu}(\mathrm{IV})$ to $\mathrm{Pu}(\mathrm{VI})$ and then diluting an aliquot of the $\mathrm{Pu}(\mathrm{VI})$ in water and allowing it to slowly reduce to $\mathrm{Pu}(\mathrm{V})$ at $\mathrm{pH} 3$. Following this procedure, up to $95 \%$ of $\mathrm{Pu}(\mathrm{VI})$ is reduced to $\mathrm{Pu}(\mathrm{V})$ within less than a week. The diluted $\mathrm{Pu}(\mathrm{V})$ stock remains stable when stored in the dark for extended periods of time (several months). 


\subsection{Preparation and characterization of intrinsic $\mathrm{Pu}(\mathrm{IV})$ colloids}

$\mathrm{Pu}(\mathrm{IV})$ hydroxides are easily obtained by rapidly increasing the $\mathrm{pH}$ of a pure acidic $\mathrm{Pu}(\mathrm{IV})$ stock solution to $>4$. The rapid increase of $\mathrm{pH}$ produces an emerald green precipitate that rapidly settles at the bottom of the vial. The precipitate remains highly aggregated and does not suspend in solution. To prepare stable suspensions of colloidal $\mathrm{Pu}(\mathrm{IV})$, we used a modified version of the sol-gel processes described in the literature [31]. Briefly, a $0.50-\mathrm{mL}$ aliquot of a $0.35-\mathrm{M} \mathrm{Pu}(\mathrm{IV})$ in $6.0-\mathrm{M}$ nitric acid was diluted in $10.0 \mathrm{~mL}$ of distilled water and the $\mathrm{pH}$ was increased to approximately 9 by adding ammonium hydroxide $\left(\mathrm{NH}_{4} \mathrm{OH} ; 25 \%\right)$. The resulting finely divided emerald green precipitate was washed six times using distilled water to remove the traces of $\mathrm{Pu}(\mathrm{VI})$ and $\mathrm{Pu}(\mathrm{III})$ that are formed as side products during the hydrolysis of $\mathrm{Pu}(\mathrm{IV})$ [31]. The solids were resuspended in distilled water, and the $\mathrm{pH}$ was adjusted to 4.26 . The suspension was heated at $80^{\circ} \mathrm{C}$ for $8 \mathrm{~h}$, cooled down, and sonicated for $30 \mathrm{~min}$. The solution was then centrifuged at $5000 \mathrm{rpm}$ for $30 \mathrm{~min}$, and the supernatant was filtered through a $0.22-\mu \mathrm{m}$ polycarbonate filter. The resulting suspension is emerald green and remains stable at low $\mathrm{pH}$ for an extended period of time.

Characterization of $\mathrm{Pu}(\mathrm{IV})$ colloidal suspensions. The characterization of the $\mathrm{Pu}(\mathrm{IV})$ colloidal suspensions was performed using a nanozetasizer instrument (Malvern Inc.) equipped with a 633-nm (red) laser. Approximately $1 \mathrm{~mL}$ of the particle suspensions was injected into a folded capillary cell with embedded electrodes and capped off with plugs. Particle size and surface charge measurements were performed, and the physical parameters for the dispersed and continuous phases were input using the instrument's 
software. The average particle size of the $\mathrm{Pu}(\mathrm{IV})$ colloids used in our studies was approximately $97 \mathrm{~nm}$ (see Figure S2 in supporting information).

\subsection{Plutonium uptake experiments and alpha spectrometry analysis}

Plutonium extraction by DIPEX-polystyrene thin films was performed for each oxidation state and $\mathrm{Pu}(\mathrm{IV})$ colloids using fresh solutions prepared from pure $\mathrm{Pu}(\mathrm{IV})$ stock solutions few days before the extraction experiments. The solutions containing plutonium in the desired chemical form (typically $2.0 \mathrm{~mL}$ ) were transferred to the planchet coated with the DIPEX-polystyrene thin film and left to equilibrate at room temperature for $2 \mathrm{~h}$. At the end of the equilibration period, the plutonium solution was removed and the planchet was washed with deionized water and left to dry before counting. For soil sample analysis, 1.0 $\mathrm{g}$ of dried soil from our collection of archived samples with known radionuclides content was equilibrated overnight with $10.0 \mathrm{~mL}$ of $8.0 \mathrm{M}$ nitric acid in the presence of several drops of hydrogen peroxide (34\%). The supernatant was separated from the soil particles by centrifugation or filtration though $0.20-\mu \mathrm{m}$ polycarbonate filters. An aliquot of the stock solution was diluted in deionized water to obtain a final concentration of 1.0-M nitric acid. An aliquot of the solution $(3.0 \mathrm{~mL})$ was deposited on the DIPEX-polystyrene thin film evenly deployed on a metallic planchet and left to equilibrate for $2 \mathrm{~h}$. Following equilibration, the thin films were washed thoroughly by deionized water, left to dry, and then counted on the alpha spectrophotometer. Samples were counted for selected nuclides using an alpha spectrometer fitted with 450-mm passivated implanted planar silicon detectors manufactured by Ortec Inc. Samples were counted from $15 \mathrm{~min}$ up to $50 \mathrm{~h}$ depending on the alpha activity and were corrected for background activity recorded using an empty chamber for similar count times. Detectors were calibrated with stainless- 
steel planchets using -traceable ${ }^{242} \mathrm{Pu},{ }^{239} \mathrm{Pu}$, and ${ }^{238} \mathrm{Pu}$ standards obtained from the National Institute of Standards and Technology. Under our settings, the detector efficiency was typically at $22.5 \%$ and the background activity was typically below 0.001 CPM in the energy range where plutonium is observed.

\section{Results}

\subsection{General considerations}

Plutonium tracers of specific oxidation states were prepared shortly before the extraction experiments from pure stock solution that are usually present at millimolar concentrations. This was performed to minimize the changes in the oxidation state that occur when the samples are diluted to tracer levels. The very low levels of most of the solutions used make it difficult to assess with certainty whether rapid redox reactions affect the redox speciation of plutonium under extremely dilute conditions. For all our experiments, we assumed that the rapid execution of the extraction experiment $(3 \mathrm{~h}$ or less) in a single equilibration procedure minimizes redox changes in solution.

\subsection{Extraction of $\mathrm{Pu}(\mathrm{III}), \mathrm{Pu}(\mathrm{IV}), \mathrm{Pu}(\mathrm{V})$, and $\mathrm{Pu}(\mathrm{VI})$}

We examined the ability of DIPEX-polystyrene thin films to extract (tracer levels of) plutonium from aqueous solution as a function of the specific oxidation state of plutonium. All extraction experiments were performed in triplicates or higher replication numbers. Control plutonium extraction experiments were also performed using untreated planchets and planchets coated with a thin film of polystyrene in the absence of DIPEX. The data in Figure 1 show the spectrum of a standard $\mathrm{Pu}(\mathrm{IV})$ solution extracted onto a 
DIPEX-polystyrene thin film and counted using an alpha spectrometer and the spectrum of an electroplated standard containing Pu-242, Pu-239, and Pu-238. The spectrum of the DIPEX film shows two well-resolved peaks at energies 5165 and $5520 \mathrm{keV}$ attributed to $\mathrm{Pu}-239 / \mathrm{Pu}-240$ and to either Am-241 or Pu-238, respectively. The spectrum of the electroplated standard shows three well-separated peaks at 4863, 5226, and $5560 \mathrm{keV}$ attributed to $\mathrm{Pu}-242, \mathrm{Pu}-239$, and $\mathrm{Pu}-238$, respectively. The full width at half maximum (FWHM) for the DIPEX-polystyrene thin film is identical to that of the electroplated standard measured at $39 \mathrm{keV}$. The spectra show that the DIPEX thin films perform as good as electroplated samples. The data in Figure 2 show the fraction of plutonium extracted as a function of the oxidation sate. The fraction of plutonium extracted onto the thin films with immobilized DIPEX is defined as the ratio between the activity retained on the thin film, as determined by alpha spectrometry and corrected for the detector counting efficiency, and the total activity in the solution determined by liquid scintillation counting (LSC). The data show that planchet controls without coating had very little affinity for plutonium binding for all oxidation states. Polystyrene thin films without DIPEX retained some plutonium and showed high variability between the samples. This was expected because polystyrene thin films are known to bind a range of metals [e.g., $\mathrm{Cu}(\mathrm{II}), \mathrm{Zn}(\mathrm{II}), \mathrm{Ni}(\mathrm{II})$, and $\mathrm{Cd}(\mathrm{II})]$; however, the exact nature of the interaction is not well defined [32]. The highest extraction ratios of $56 \pm 5 \%$ and $37.2 \pm 3 \%$ after $2 \mathrm{~h}$ of equilibration time were observed for $\mathrm{Pu}(\mathrm{IV})$ and $\mathrm{Pu}(\mathrm{III})$, respectively. These extraction experiments were performed in $1.0 \mathrm{M}$ nitric acid to prevent $\mathrm{Pu}(\mathrm{III})$ and $\mathrm{Pu}(\mathrm{IV})$ from hydrolysis and precipitation, which occurs rapidly at $\mathrm{pH}$ as low as 2.5 for $\mathrm{Pu}(\mathrm{IV})$. The extraction of $\mathrm{Pu}(\mathrm{III})$ and $\mathrm{Pu}(\mathrm{IV})$ by DIPEX-polystyrene thin films was significantly 
higher than that of the controls without DIPEX, which indicates that DIPEX is responsible for plutonium extraction. The fractions of $\mathrm{Pu}(\mathrm{V})$ and $\mathrm{Pu}(\mathrm{VI})$ extracted, $2.8 \pm$ $2.2 \%$ and $3.04 \pm 1.2 \%$, respectively, after $2 \mathrm{~h}$ of equilibration were only slightly better than those of the controls. The amount of plutonium extracted increased when the contact time was increased for all oxidation states.

\subsection{Kinetics of plutonium extraction onto DIPEX-polystyrene thin films}

We examined the rate of plutonium extraction onto DIPEX-polystyrene thin films by monitoring the activity retained on the films over time. At the start of the experiment, the same amount of solution $(2.0 \mathrm{~mL})$ was transferred to all planchets, and at selected times, individual samples were removed, the solution was transferred, and the planchets were washed and left to dry before counting. This experiment allowed us to examine the extraction of plutonium onto the DIPEX-polystyrene films as a function of time. The data in Figure 3 show that for all oxidation states, the fraction of plutonium retained on the film increased with increasing contact time. At very long equilibration times ( $24 \mathrm{~h})$, $\mathrm{Pu}(\mathrm{IV})$ retention exceeded $80 \%$. However, at long equilibration times, some of the solutions evaporated, which affected the concentration of plutonium in the solution and therefore the equilibrium between the solution and the thin film. For all oxidation states, the equilibrium conditions were reached after about $3 \mathrm{~h}$, after which very little additional plutonium transferred to the thin film.

\subsection{Dependencies of plutonium extraction onto DIPEX-polystyrene thin films on the initial solution concentrations}


For all oxidation states, the amount of plutonium extracted onto the DIPEX-polystyrene thin films was directly correlated with the concentrations of plutonium in the solution. The data in Figure 4 show that the extraction of $\mathrm{Pu}(\mathrm{IV})$ is linearly correlated to the concentration of plutonium in the solution. $\mathrm{Pu}(\mathrm{III}), \mathrm{Pu}(\mathrm{IV}), \mathrm{Pu}(\mathrm{V})$, and $\mathrm{Pu}(\mathrm{VI})$ extractions onto the DIPEX films were also linearly proportional to the activity in solution (data not shown). However, at longer equilibration times, the correlation between the plutonium extracted to the thin films and the concentration of plutonium in the solution deviates from linearity, presumably because of the solution evaporation and the subsequent change in plutonium concentration and the state of the equilibrium between the solid films and the aqueous solution. The data also show that saturation conditions were not attained even for the highest concentration used, which implies that the number of functional groups (binding sites) available for plutonium uptake remains in large excess relative to plutonium concentration. This shows that the fraction of plutonium retained on the thin film is constant across a large range of concentration and is only significantly affected by the equilibration time.

\subsection{Parameters affecting plutonium partitioning onto DIPEX-polystyrene thin}

\section{films}

Plutonium retention on DIPEX-polystyrene thin films is affected by solution conditions such as $\mathrm{pH}$ and the presence of other competing cations. We examined the effects of nitric acid concentration and the presence of reductants such as hydroxylamine on plutonium extraction. The data in Figure 5 show the effects of nitric acid concentration and hydroxyl amine addition on the extraction of plutonium. Figure 5A shows that nitric 
acid concentrations did not significantly affect the extraction of $\mathrm{Pu}(\mathrm{IV})$. We examined nitric concentrations for up to $12 \mathrm{M}$ (data not presented) and did not observe significant changes in the fraction of $\mathrm{Pu}(\mathrm{IV})$ extracted. However, nitric acid concentration had stronger effects on the extraction of $\mathrm{Pu}(\mathrm{III}), \mathrm{Pu}(\mathrm{V})$, and $\mathrm{Pu}(\mathrm{VI})$. This was expected because nitric acid tends to stabilize $\mathrm{Pu}(\mathrm{IV})$ over all other oxidation states. We observed a continuous increase in the plutonium retention on the thin film with immobilized DIPEX for $\mathrm{Pu}(\mathrm{III}), \mathrm{Pu}(\mathrm{V})$, and $\mathrm{Pu}(\mathrm{VI})$ with increased contact time. A similar enhancement in $\mathrm{Pu}(\mathrm{V})$ and $\mathrm{Pu}(\mathrm{VI})$ retention on the DIPEX-polystyrene thin films was observed when hydroxyl amine was added to the solution (Figure 5 B). This was also expected because hydroxyl amine rapidly reduces $\mathrm{Pu}(\mathrm{V})$ and $\mathrm{Pu}(\mathrm{VI})$ to $\mathrm{Pu}(\mathrm{IV})$ and $\mathrm{Pu}(\mathrm{III})$, which are extracted more effectively by the DIPEX-polystyrene thin films.

\subsection{Colloidal Pu(IV) extraction onto DIPEX-polystyrene thin films}

We examined the partitioning of intrinsic $\mathrm{Pu}(\mathrm{IV})$ colloids between aqueous solutions and the thin film with immobilized DIPEX at near-neutral $\mathrm{pH}$ conditions and at different nitric acid concentrations. We also examined the same in controls with untreated planchets and planchets coated with polystyrene only. The data in Figure 6A show that colloidal plutonium is poorly retained by the DIPEX-polystyrene thin films. The fraction of plutonium extracted is only slightly higher than that of the controls. The data in Figure 6B show the spectra of the plutonium standards used to calibrate the instrument along with the data for $\mathrm{Pu}(\mathrm{IV})$ colloids extraction at different nitric acid concentrations. The count data in these spectra were not corrected for the instrument counting efficiency. We found that the concentration of nitric acid in the aqueous solution did not significantly 
affect the partitioning of colloidal plutonium between the two phases. The data from this series of tests were obtained using one data point for each acid concentration and showed significant scattering but did not indicate any dependence of the fraction of plutonium extracted on the aqueous solution acidity. This is true for short equilibration times during which the plutonium colloids were not solubilized by acid dissolution. However, at longer equilibration times, an increase in plutonium uptake was observed and is attributed to the solubilization of $\mathrm{Pu}(\mathrm{IV})$ colloids. These data show that thin films with immobilized DIPEX did not have any significant affinity for colloidal plutonium.

\subsection{Detection limit and application of DIPEX-polystyrene thin films for the separation of plutonium from environmental samples}

Extraction of plutonium from tap water containing trace amounts of plutonium was examined at neutral $\mathrm{pH}(\mathrm{pH}=6.21)$ and in $1.0 \mathrm{M}$ nitric acid. Triplicate samples were prepared for each condition. The experiment was performed by the addition of individual planchets coated with DIPEX-polystyrene films to $100-\mathrm{mL}$ solutions containing trace levels of $\mathrm{Pu}(\mathrm{IV})$. The planchets were left to equilibrate for $2 \mathrm{~h}$. After equilibration, the planchets were removed, washed thoroughly with deionized water, dried, and counted by alpha spectrometry. The count data (Figure S3 in supporting information) show that very little plutonium is extracted onto the DIPEX-polystyrene thin films at neutral $\mathrm{pH}(\mathrm{pH}=$ 6.21 ) and in 1.0 $\mathrm{M}$ nitric acid. The fractions of plutonium extracted were $0.15 \pm 0.05 \%$ and $0.07 \pm 0.05 \%$ in $1.0 \mathrm{M}$ nitric acid and at $\mathrm{pH} 6.21$, respectively. The factions extracted were calculated on the basis of the total activity in solution determined by LSC. The low extractability of plutonium observed could be due to the disproportionation of $\mathrm{Pu}(\mathrm{IV})$ or 
formation of colloidal $\mathrm{Pu}(\mathrm{IV})$, especially at neutral $\mathrm{pH}$. It is also likely that the very low surface area of the thin films $\left(40 \mathrm{~mm}^{2}\right)$ relative to the large volume $(100 \mathrm{~mL})$ of the solution used would require a much longer equilibration time for the sorption to reach equilibrium. Competition from divalent cations such as $\mathrm{Ca}^{2+}$ and $\mathrm{Mg}^{2+}$ present in water at much higher concentrations relative to plutonium is also likely to reduce plutonium capture.

Extraction of plutonium from contaminated soil samples was performed using soil samples from Rocky Flats [33]. The experiment was performed by acid leaching the soil samples using 8.0 M nitric acid in the presence of trace amounts of hydrogen peroxide overnight and the equilibration of a diluted aliquot of the leach solution (in 1.0 M nitric acid) with the DIPEX thin films for $1 \mathrm{~h}$. Aliquots of the leach solutions were also counted by LSC to determine the total radioactivity of the solutions. A control sample was also prepared by evaporation of an aliquot of the leached solution to dryness on a stainlesssteel planchet disc without thin film coating. A second control was also prepared by flaming an aliquot of the leached solution on a stainless-steel planchet for comparison. The count data are shown in Figure 7. The alpha spectrum obtained by analyzing the polystyrene thin film with immobilized DIPEX showed two well-resolved peaks at peak energies 5165 and $5560 \mathrm{keV}$ with peak area ratio 5505/5155 of 0.032. The well-resolved peak with a FWHM of $36 \mathrm{keV}$ at $5165 \mathrm{keV}$ is attributed to $\mathrm{Pu}-239 / \mathrm{Pu}-240$ and the peak at $5560 \mathrm{keV}$ to either Am-241 or Pu-238. Analysis of the flamed stainless-steel control also showed two slightly broader peaks at 5165 and $5560 \mathrm{keV}$. The FWHM of the peak at $5155 \mathrm{keV}$ attributed to $\mathrm{Pu}-239 / \mathrm{Pu}-240$ was $48 \mathrm{keV}$. The control dried directly on the stainless-steel planchet disc without DIPEX showed two broad peaks with energy levels 
that were not well defined. The data show that the planchets with immobilized DIPEX thin film offer an excellent and rapid way for the qualitative detection of plutonium in complex natural matrices. The peak resolution is sufficient to identify plutonium and americium radio isotopes. The background is very low compared to the controls and shows the ability of the DIPEX-polystyrene thin films to extract plutonium and americium from aqueous media containing other cations and transition metals.

\section{Discussion}

P,P'-di(2-ethylhexyl) methanediphosphonic acid (DIPEX) is a bidentate chelating ligand containing a diphosphonic acid functional group (Scheme 1). It is known for its high affinity for actinides in the tri-, tetra-, and hexavalent oxidation states. It also coordinates a range of other metals such as $\mathrm{Fe}^{3+}, \mathrm{Fe}^{2+}, \mathrm{Bi}^{3+}, \mathrm{Ti}^{4+}, \mathrm{Ca}^{2+}$, and $\mathrm{Ra}^{2+}[27,28]$. The extraction of actinide species and other metals by liquid DIPEX is affected by the nature of the solvent used (which affects the ligand's aggregation properties), the concentration of nitric acid, and the stoichiometric ratio between the ligand and the targeted metal [27]. DIPEX can form monodentate, bidentate, and polydentate complexes with stoichiometries 1:1, 1:2, and up to 1:3 metal:DIPEX depending on the metal and the DIPEX concentration. Both phosphonic and alcohol groups are involved in metal coordination [28,34-37]. Liquid DIPEX has the highest extraction efficiency in nonpolar solvents and acidities in 0.1-1.0 $\mathrm{M}$ range [27,28]. There are no details in the literature on the complexation of the different oxidation states of plutonium by DIPEX. However, some data on the extraction of $\mathrm{Pu}(\mathrm{IV})$ along with extraction data for $\mathrm{Am}(\mathrm{III})$, Th(IV), 
$\mathrm{Np}(\mathrm{V})$, and $\mathrm{U}(\mathrm{VI})$ exist, some of which could be used as analogues for the different oxidation states of plutonium.

We compared the extraction of the different oxidation states of plutonium by DIPEX-polystyrene films obtained here with the data from previous studies on the extraction of different actinides by liquid DIPEX. The extraction coefficients determined here were converted to extraction weight distribution coefficients defined as $D=\left(\frac{A_{0}-A_{f}}{A_{f}}\right)\left(\frac{V}{w}\right)$

where $A_{0}$ and $A_{f}$ represent the solution activity before and after the extraction, $V$ is the volume of the aqueous solution equilibrated with the solution containing the extractant, and $\mathrm{W}$ the weight of the extractant used. We assumed an unchanged volume of the aqueous solution $\mathrm{V}=2.0 \mathrm{~mL}$ and assumed that the weight of DIPEX incorporated in each thin film remained constant at $0.0166 \mathrm{~g}$ determined as one-tenth of the average weight of the thin film deposited on the planchet. Table 1 presents the calculated weight distribution ratios for DIPEX-polystyrene thin films and the data from previous studies for several other actinides. The weight distribution ratios calculated for the different oxidation states for the DIPEX-polystyrene thin films, $\mathrm{Pu}(\mathrm{IV})>\mathrm{Pu}(\mathrm{III})>\mathrm{Pu}(\mathrm{VI}) \cong \mathrm{Pu}(\mathrm{V})$ $\cong$ colloidal $\mathrm{Pu}(\mathrm{IV})$, were more than $10^{3}$ times lower than the distribution ratios observed for liquid DIPEX, for which the distribution ratios were about the same for all oxidation states. The data in Table 1 show that for all the oxidation states, the weight distribution ratios determined in this study are at least $10^{3}$ times lower than the values reported in the literature for liquid DIPEX. The ratios between the values determined for liquid DIPEX and DIPEX-polystyrene for $\mathrm{Pu}(\mathrm{III})$ and $\mathrm{Pu}(\mathrm{IV})$ are approximately an order of magnitude higher than the ratios for $\mathrm{U}(\mathrm{VI})$ and $\mathrm{Pu}(\mathrm{VI})$, indicating a significant loss of efficiency of 
DIPEX-polystyrene thin films toward the extraction of $\mathrm{Pu}(\mathrm{VI})$ and $\mathrm{U}(\mathrm{VI})$. The general loss of extraction efficiency observed for the DIPEX-polystyrene thin films compared to that for liquid DIPEX for all metals was expected because the amount of ligand used is not completely available for metal ion extraction. Effectively, given the aggregation properties of DIPEX [28], we expect that a large amount of DIPEX will be present in the bulk of the thin film and unavailable for metal complexation. The immobilization of DIPEX within a rigid structure is also expected to reduce the ligand's ability to accommodate the preferred geometry of the metal and is also expected to affect DIPEXpolystyrene thin films' ability to extract metals. However, the near complete loss of affinity toward $\mathrm{U}(\mathrm{VI})$ and $\mathrm{Pu}(\mathrm{VI})$ by DIPEX-polystyrene thin films was unexpected. We are unsure of the reason behind the large drop in the affinity of DIPEX for $\mathrm{Pu}(\mathrm{VI})$ and $\mathrm{U}(\mathrm{VI})$ binding, but it is likely that immobilized DIPEX is unable to adopt the appropriate orientation necessary for Pu(VI) and U(VI) binding. Additional discussion on functionalized DIPEX thin films' preparation and metal extraction efficiency is published elsewhere [38].

In the solid form, DIPEX is likely to be less flexible and functional groups from different molecules will likely be needed to achieve the coordination of the metal at the surface. Considering that $\mathrm{Pu}(\mathrm{IV})$ and $\mathrm{Pu}(\mathrm{III})$ extractions exhibit little acid dependencies over a large concentration range ( 0.1 up to $\left.15 \mathrm{M} \mathrm{HNO}_{3}\right)$, it is likely that their extraction involves coordination only from the phosphonic groups and in a monodentate or polydentate coordination mode (Scheme 2). The specific coordination geometries of $\mathrm{Pu}(\mathrm{III})$ and $\mathrm{Pu}(\mathrm{IV})$ make it possible for functional $\mathrm{P}=\mathrm{O}$ and $\mathrm{P}-\mathrm{OH}$ groups available on the surface to bind metals (Scheme II). It is much more difficult for multiple $\mathrm{P}=\mathrm{O}$ and $\mathrm{P}-\mathrm{OH}$ 
groups available on the surface to bind $\mathrm{U}(\mathrm{VI})$ and $\mathrm{Pu}(\mathrm{VI})$. Both $\mathrm{U}(\mathrm{VI})$ and $\mathrm{Pu}(\mathrm{VI})$ are coordinated by two oxygen atoms in linear $\mathrm{O}=\mathrm{M}=\mathrm{O}$ ions, which only allow coordination to the uranium and plutonium centers on the equatorial planes, making it more difficult for the binding groups available on the surface to accommodate multidentate coordination of the targeted metals.

The uptake data in Figure 4 show that saturation conditions are not attained even at the highest concentrations used, up to $2.510^{5} \mathrm{CPM} / \mathrm{mL}$. Under our tracer tests, the available sites for plutonium extraction were always in large excess relative to the amount of plutonium in solution. The slope of the plot of the amount of plutonium retained on the thin films relative to the activity in solution is reasonably linear for all oxidation states tested. This is also a confirmation that even under the highest concentrations of plutonium tested, thin film saturation conditions were not attained. However, the uptake of plutonium of all oxidation states by DIPEX immobilized in polystyrene is slower than the uptake rates observed with liquid DIPEX [28]. The data in Figure 3 show that for all oxidation states, at least $3 \mathrm{~h}$ are required to reach equilibrium. This is significantly higher than the equilibration time observed for liquid DIPEX, which varies from 5 to $20 \mathrm{~min}$ for most actinides and transition metals [28,34-37]. Under our extraction conditions, rapid evaporation of the aqueous solution in equilibrium with the DIPEX thin film affects the profile of plutonium uptake over time because it slowly increases its concentration and affects the partitioning equilibrium. This equilibration time is even slower than metal uptake kinetics observed for other extraction resins, which typically require about $10 \mathrm{~min}$ to attain equilibrium [37]. The slow uptake kinetics observed for all oxidation states may be because of the aggregation of immobilized 
DIPEX in the bulk of rigid hydrophobic polystyrene that prevents the ligand from adopting optimal geometries and stoichiometries required to accommodate metal binding. We observed little to no variation of $\mathrm{Pu}(\mathrm{IV})$ extraction as a function of nitric acid concentration for up to $10.0 \mathrm{M}$ (Figure 5). However, nitric acid concentration positively affected the extraction of $\mathrm{Pu}(\mathrm{III}), \mathrm{Pu}(\mathrm{V})$, and $\mathrm{Pu}(\mathrm{VI})$. The extraction of plutonium of all oxidation states except $\mathrm{Pu}(\mathrm{IV})$ increased slowly with time under high acidities. This is explained by the tendency of strong nitric acid conditions to stabilize of $\mathrm{Pu}(\mathrm{IV})$ over all other oxidation states. Our data also show that addition of hydroxyl amine, which rapidly reduced oxidized $\mathrm{Pu}(\mathrm{V})$ and $\mathrm{Pu}(\mathrm{VI})$ to $\mathrm{Pu}(\mathrm{III})$ and $\mathrm{Pu}(\mathrm{IV})$, enhances the extraction of plutonium onto DIPEX-polystyrene thin films.

The extraction of colloidal plutonium is expected to be the most challenging because of the low reactivity of plutonium oxide surfaces and the tendency of plutonium colloids to form aggregates or to associate strongly with positively charged natural particles such as clay, limiting their access to surface extractants [38]. Our data show that $\mathrm{Pu}(\mathrm{IV})$ colloids are not extracted by the thin films with immobilized DIPEX.

Acidification, which increases the net positive charge on plutonium particles (which have a point of isoelectric charge at 8.7) and helps disperse plutonium particles, does not effect plutonium uptake by the thin films with immobilized DIPEX. Although the data in Figure 5 show a slight increase in plutonium uptake in $1.0 \mathrm{M}$ nitric acid relative to the treatment at $\mathrm{pH} 4.3$, the difference overall is not significant. However, at longer equilibration times, acid dissolution drives up the extraction of plutonium onto the thin films. Addition of small amounts of surfactants such as aerosol and ligands that could modify plutonium colloid surfaces and help improve their partitioning onto the thin film did not produce any 
measurable improvement (data not shown). Plutonium colloid extraction from environmental samples is challenging and requires special attention because colloidal plutonium species represent the main form that is likely to be present in significant concentrations under environmental conditions. Plutonium colloids carry a very strong positive charge and under most conditions are associated with natural colloids such as clay colloids, which carry a strong negative charge. This behavior makes it challenging for membranes and solid surfaces to directly extract plutonium, and they will require chemical processing to free plutonium from environmental matrices and make it available for extraction. Our examination of plutonium extraction from soils with contaminated plutonium performed by directly equilibrating soil extracts with thin films with immobilized DIPEX did not produce good results, which was expected because our thin films do not extract plutonium oxy(hydr)oxides, the dominant form present in environmental samples. However, acid leaching of the soil samples using $8.0 \mathrm{M}$ nitric acid and subsequent extraction of plutonium from the leach solutions using DIPEXpolystyrene films was very effective and can be easily implemented to qualitatively analyze plutonium in soils using minimal sample processing.

\section{Conclusion}

Thin films of DIPEX-polystyrene were tested for their ability to extract plutonium from solutions containing $\mathrm{Pu}(\mathrm{III}), \mathrm{Pu}(\mathrm{IV}), \mathrm{Pu}(\mathrm{V}), \mathrm{Pu}(\mathrm{VI})$, and colloidal $\mathrm{Pu}(\mathrm{IV})$ and were determined to have varying degrees of extraction efficiencies depending on the specific oxidation state of plutonium and its chemical form. The oxidation states $\mathrm{Pu}(\mathrm{III})$ and $\mathrm{Pu}(\mathrm{IV})$ were extracted from solution at $37 \%$ and $56 \%$ ratios, respectively, after $2 \mathrm{~h}$ of 
equilibration time. The oxidation states $\mathrm{Pu}(\mathrm{V})$ and $\mathrm{Pu}(\mathrm{VI})$ were extracted less effectively with extraction ratios of $2.8 \%$ and $3.0 \%$, respectively. However, $\mathrm{Pu}(\mathrm{V})$ and $\mathrm{Pu}(\mathrm{VI})$ were extracted more efficiently when reduced to lower oxidation states by the addition of reductants such as hydroxyl amine. The thin films with immobilized DIPEX do not have any affinity for colloidal $\mathrm{Pu}(\mathrm{IV})$. For all oxidation states, the weight distribution ratios

calculated for DIPEX-polystyrene thin films were more than $10^{3}$ times lower than the weight distribution ratios calculated for liquid DIPEX. This is attributed to the inability of the DIPEX ligand in the DIPEX-polystyrene structure to adopt appropriate geometries to accommodate the specific coordination geometry of the metal. Our results indicate that the polystyrene thin films with immobilized DIPEX are effective only for the rapid extraction of plutonium present in the $\mathrm{Pu}(\mathrm{III})$ and $\mathrm{Pu}(\mathrm{IV})$ oxidation states. However, the films were found to be less performant when used with large volumes of sample because of the very low surface area of the film.

\section{Acknowledgment}

Funding for this project was provided by the NA-22 Program. This work was conducted at the Los Alamos National Laboratory, Operated by Los Alamos National Security, LLC for the U.S. Department of Energy's NNSA. 


\section{References}

[1] W. Runde. The Chemical Interactions of Actinides in the Environment, Los Alamos Sci. 26 (2000) 392-416.

[2] H. Nitsche, S.C. Lee , and R.C. Gatti , Determination of Plutonium Oxidation States at Trace Levels Pertinent to Nuclear Waste Disposal, J. Radioanal. Nucl. Chem. 124(1) (1988) 171-185.

[3] G.R. Choppin, Actinide speciation in the environment, J. of Radioanal. and Nuc. Chem., 273(3) (2007) 695-703.

[4] P. Lindahl, P. Worsfold, M. Keith-Roach, M.B. Andersen, P. Kershaw, K. Leonard, M.S. Choi, D. Boust, P. Lesueur, Temporal record of Pu isotopes in inter-tidal sediments from teh northeastern Irish Sea, The Science of the Total Environment, 409(23) (2011) $5020-5025$.

[5] I. Levy, P.P. Povinec, M. Aoyama, K. Hirose, J.A. Sanchez-Cabeza, J.-F. Comanducci, J. Gastauda, M. Eriksson, Y. Hamajima, C.S. Kim, K. Komura, I. Osvatha, P. Roos, S.A. Yim, Marine anthropogenic radiotracers in the Southern Hemisphere: New sampling and analytical strategies, 89(1-4) (2011) 120-133.

[6] P.P. Povinec, H.D. Livingston, S. Shima, M. Aoyama, J. Gastaud, I. Goroncy, K. Hirose, ; L. Huynh-Ngoc, Y. Ikeuchi, T. Ito, J. La Rosa, L.L.W. Kwong, S.H. Lee, H. 
Moriya, S. Mulsow, B. Oregioni, H. Pettersson, O. Togawa, IAEA '97 expedition to the NW Pacific Ocean-results of oceanographic and radionuclide investigations of the water column, Deep Sea Research Part II: Topical Studies in Oceanography, 50(17-21) (2003) 2607-2637.

[7] S.L. Maxwell, B.K. Culligan, G.W. Noyes, Rapid separation method for actinides in emergency air filter samples, Appl. Radiat. Isot. 68(12) (2010) 2125-2131.

[8] J.J. Wang, I.J. Chen, Chiu J.H. Sequential isotopic determination of plutonium, thorium, americium, strontium and uranium in environmental and bioassay samples. Appl. Radiat. Isot., 61(2-3) (2004), p. 299-305.

[9] H. Michel, D. Levent, V. Barci, G. Barci-Funel, C. Hurel, Soil and sediment sample analysis for the sequential determination of natural and anthropogenic radionuclides, Talanta. 74(5) (2008) 1527-1533.

[10] J.J. Harrison, A. Zawadzki, R. Chisari, H.K. Wong Separation and measurement of thorium, plutonium, americium, uranium and strontium in environmental matrices, $\mathrm{J}$. Environ. Radioact. 102(10) (2011) 896-900.

[11] L. Pourcelot, B. Boulet, C. Le Corre, J. Loyen, C. Fayolle, D. Tournieux, W. Van Hecke, B. Martinez, J. Petit, Isotopic evidence of natural uranium and spent fuel uranium releases into the environment, J. Environ. Monit. 13(2) (2011) 355-361. 
[12] N. Guerin, R. Calmette, T. Johnson, D. Lariviere, Multi-dimensional extraction chromatography of actinides for alpha and mass spectrometry Source: Analytical Methods, Anal. Methods, 3(7) (2011) 1560-1567.

[13] J. Zheng, M. Yamada, Investigating Pu and U isotopic compositions in sediments: a case study in Lake Obuchi, Rokkasho Village, Japan using sector-field ICP-MS and ICPQMS. J. Environ. Monit. 7(8) (2005) 792-797.

[14] H. Surbeck, Alpha spectrometry sample preparation using selectively adsorbing thin films, Applied. Radiation. Isotopes. 53(1-2) (2000) 97-100.

[15] I. Pantchev, P. Farquet, H. Surbeck, T. Meyer, Surface modified Nylon 6,6 and application for adsorption and detection of uranium in potable water, Reactive $\&$ Functional Polymers, 67(2) (2007) 127-135.

[16] E.R. Gonzales, D.S. Peterson, Rapid radiochemical sample preparation for alpha spectrometry using polymer ligand films, J. of Radioanal. and Nucl. Chem. 282(2) (2009) 543-547.

[17] W. David LocklairJoseph, M. MannionScott, M. HussonBrian, A. Powell, Uptake of plutonium on a novel thin film for use in spectrometry, J. of Radioanal. and Nucl. Chem. 307(3) (2016) 2333-2338. 
[18] V. Chavan, V. Thekkethil, A. K. Pandey, M. Iqbal, J. Huskens, S. S. Meena, A. Goswami, W. Verboom, Assembled diglycolamide for f-element ions sequestration at high acidity, Reactive and Functional Polymers, 74 (2014) 52-57.

[19] M. Chanda , G.L. Rempel, Removal of uranium from acidic sulfate solution by ion exchange on poly(4-vinylpyridine) and polybenzimidazole in protonated sulfate form, Reactive Polymers, 17(2) (1992) 159-174.

[20] A.W. Trochimczuk, Ph.E. Horwitz, S.D. Alexandratos, Complexing Properties of Diphonix, a New Chelating Resin with Diphosphonate Ligands, Toward Ga(III) and In(III), Separ. Sci. Technol. 29 (4) (1994) 543-549.

[21] A. Ouerghui, H. Elamari, S. Ghammouri, R. Slimi, F. Meganem, C. Girard, Polystyrene-supported triazoles for metal ions extraction: Synthesis and evaluation, Reactive and Functional Polymers, 74 (2014) 37-45.

[22] S.D. Alexandratos, W. A. Trochimczuk, D.W. Crick, Ph.E. Horwitz, R.C. Catrone, R. Chiarizia, Synthesis and Ion-Complexing Properties of a Novel Polymer-Supported Reagent with Diphosphonate Ligands, Macromolecules, 29(3) (1996) 1021-1026. 
[23] M.R. Lutfor, S. Silong, W.M.Z.W. Yunus, M.Z.A. Rahman, M. Ahmed, M.J. Haron, New polymer bearing hydroxamic acid chelating resin for binding of heavy metal ions, J. Chem. Res. 10 (2001) 450-451(2).

[24] Y. G. Ko, J. M. Lim, H. Lee, K. H. Chung, M. J. Kang, Sequential separation method for the determination of uranium and thorium in soil using diamyl amylphosphonate and Aliquat ${ }^{3} 36$ impregnated polymer resins. Reactive and Functional Polymers, 106 (2016) 43-50.

[25] S. Şimşek, U. Ulusoy, Adsorptive properties of sulfolignin-polyacrylamide graft copolymer for lead and uranium: Effect of hydroxilamine-hydrochloride treatment, Reactive and Functional Polymers, 73(1) (2013) 73-82.

[26] R. E. Wilson, O. Schwindt, P. Fenter, Exploitation of the sorptive properties of mica for the preparation of higher-resolution alpha-spectroscopy samples, Radiochemica Acta 98(7) (2010) 431-436.

[27] E.P. Horwitz, R. Chiarizia, and M.L. Dietz, DIPEX: A New Extraction Chromatographic Material for the Separation and Preconcentration of Actinides from Aqueous Solution, Reactive \& Functional Polymers, 33 (1997) 25-36.

[28] R. Chiarizia, D. R. McAlister, A. W. Herlinger, Solvent Extraction by Dialkylsubstituted Diphosphonic Acid in a Depolymerizing Diluent. Fe(III) and Actinide Ions. 
Solvent Extraction and Ion Exchange, 19(3) (2001) 415-440.

[29] J.M. Cleveland.

The chemistry of plutonium By. La Grange Park, Illinois 60525, American Nuclear Society (1979)

[30] R. Guillaumont, T. Fanghanel, J. Fuger, I. Grenthe, V. Neck, D. Palmer, M. Rand Update on the Chemical Thermodynamics of Uranium, Neptunium, Plutonium, Americium and Technetium. Issy-les-Moulineaux, France: OECD Publica- tions, (2003) 313-332.

[31] M. H. Lloyd, R. G. Haire, The chemistry of plutonium in sol-gel processes. Radiochim. Acta, 25(3-4) (1978) 139-148.

[32] N.A. Bagrovskaya, O.V. Alekseeva, Sorption properties of fullerene-modified polystyrene, Fizikokhimiya Poverkhnosti i Zashchita Materialov, 48(2) (2012) 197-200.

[31] D.L. Clark, D.R. Janecky, and L.J. Lan, Science-based cleanup of Rocky Flats, Physics Today, 59(9) (2006) 34-40.

[34] M.I. Litaor, Plutonium contamination in soils in open space and residential areas near Rocky Flats, Health Physics, 76(2) (1999) 171-179. 
[35] R. Chiarizia, A. W. Herlinger, E. P. Horwitz, Metal extraction by alkyl substituted diphosphonic acids part 3. P,P',-Di(2-Ethylhexyl) ethanediphosphonic acid solvent extraction study, Solvent Extraction and Ion Exchange 15(3) (1997) 417-431.

[36] R. Chiarizia, E. P. Horwitz, P. G. Rickert, A. W. Herlinger, Metal extraction by alkyl substituted diphosphonic acids part 1. P,P',-Di(2-Ethylhexyl) Methanediphosphonic acid, Solvent Extraction and Ion Exchange 14(5) (1996) 773-792.

[37] A. W. Herlinger, J. R. Ferraro, R. Chiarizia, E. P. Horwitz, An investigation of P, P'di(2-ethylhexyl) methanediphosphonic acid and some of its metal complexes, Polyhedron 16 (1997) 1843-1854.

[38] A.I. Abdel-Fattah, D. Zhou, H. Boukhalfa, S. Tarimala, S.D. Ware, A.A. Keller, Dispersion Stability and Electrokinetic Properties of Intrinsic Plutonium Colloids: Implications for Subsurface Transport, Environ. Sci. Technol. 47(11) (2013) 5626-5634.

[39] E. R. Gonzales, A. L. Klingensmith, D. S. Peterson, Rapid Separation and Extraction of Radioactive Analytes onto Filters and Surfaces, Proceedings in Radiochimica Acta, 1 (2011) 195-200. 


\section{Tables Caption.}

Table 1. Weight distribution ratios (D) calculated for each oxidation state of plutonium and compared with values from literature. 


\section{Figure Captions.}

Figure 1. Alpha spectrum of a Pu(IV) solution extracted on a DIPEX-polystyrene thin film (red plain line) along with the spectrum of an electroplated standard containing $\mathrm{Pu}$ 242, Pu-239, and Pu-238 (black dotted line).

Figure 2. Extraction of pure plutonium oxidation states onto polystyrene thin films with immobilized DIPEX. The fraction of plutonium extracted is defined as the ratio between the amount of plutonium retained on the thin film and the total amount of plutonium equilibrated with the thin film. Conditions: (1) $\mathrm{Pu}(\mathrm{IIII}),\left[\mathrm{H}^{+}\right]=1.0 \mathrm{M} \mathrm{HNO}_{3}$; (2) $\mathrm{Pu}(\mathrm{IV})$, $\left[\mathrm{H}^{+}\right]=1.0 \mathrm{M} \mathrm{HNO}_{3}$; (3) $\mathrm{Pu}(\mathrm{V}), \mathrm{pH}=5.14$; (4) $\mathrm{Pu}(\mathrm{VI}), \mathrm{pH}=6.40$. All samples were equilibrated at an ambient temperature of $23{ }^{\circ} \mathrm{C}$ for $2 \mathrm{~h}$. Error bars represent the standard deviation calculated from the average of three independent measurements.

Figure 3. Profiles of plutonium extraction onto DIPEX-polystyrene thin films as a function of plutonium oxidation state. Conditions: (1) $\mathrm{Pu}(\mathrm{IIII}),\left[\mathrm{H}^{+}\right]=1.0 \mathrm{M} \mathrm{HNO}_{3}$; (2) $\mathrm{Pu}(\mathrm{IV}),\left[\mathrm{H}^{+}\right]=1.0 \mathrm{M} \mathrm{HNO}_{3} ;$ (3) $\mathrm{Pu}(\mathrm{V}), \mathrm{pH}=5.14$; (4) $\mathrm{Pu}(\mathrm{VI}), \mathrm{pH}=6.40$.

Figure 4. Profile of $\mathrm{Pu}(\mathrm{IV})$ extraction onto DIPEX-polystyrene thin films as a function of $\mathrm{Pu}(\mathrm{IV})$ concentration in solution. Conditions: $(\mathrm{Pu}(\mathrm{IV})(\mathbf{\square})$, - Linear correlation) $[\mathrm{Pu}(\mathrm{IV})]$ $=$ variable. Equilibration time $=4 \mathrm{~h}$.

Figure 5. Parameters affecting plutonium partitioning onto DIPEX-polystyrene thin films. (A) Effect of nitric acid on $\mathrm{Pu}(\mathrm{IV})$ extraction. Conditions: $[\mathrm{Pu}(\mathrm{IV})]=50 \mathrm{CPM}$, 
equilibration time $=1 \mathrm{~h}$, ionic strength was not adjusted. (B) Effect of hydroxyl amine addition on $\mathrm{Pu}(\mathrm{V})$ and $\mathrm{Pu}(\mathrm{VI})$ extraction. Conditions: neutral conditions $[\mathrm{pH}=5.14$ for $\mathrm{Pu}(\mathrm{V})$ and $\mathrm{pH}=6.40$ for $\mathrm{Pu}(\mathrm{VI})]$, no hydroxylamine addition. Hydroxyl amine addition, [hydroxylamine- $\mathrm{HCl}]=0.8 \mathrm{mg} / \mathrm{mL},\left[\mathrm{HNO}_{3}\right] 1.0 \mathrm{M}$, equilibration time $=2 \mathrm{~h}$.

Figure 6. Extraction of $\mathrm{Pu}(\mathrm{IV})$ colloids by DIPEX-polystyrene thin films (A), Conditions: $\mathrm{pH}=4.30$ and $1.0 \mathrm{M}$ nitric acid, $[\mathrm{Pu}(\mathrm{IV})$ colloids $]=50 \mathrm{CPM}$, equilibration time $=2 \mathrm{~h}$, ionic strength was not adjusted. Alpha spectra were recorded for the films treated with colloidal suspensions of $\mathrm{Pu}(\mathrm{IV})$ at different nitric acid concentration along with the spectrum of an electroplated standard containing $\mathrm{Pu}-242, \mathrm{Pu}-238$, and $\mathrm{Pu}-238$ (B), Conditions: $\left[\mathrm{H}^{+}\right]=$variable, equilibration time $=45 \mathrm{~min},[\mathrm{Pu}(\mathrm{IV})$ colloids $]=100$ CPM.

Figure 7. Alpha spectra recorded for a DIPEX thin film used to extract plutonium from acid leachates obtained from a contaminated soil sample (purple ----) along with control spectra obtained for the same leach solution fixed on a stainless-steel plate by evaporation (blue - - - ) and flaming (red -). 
Tables.

Table 1.

\begin{tabular}{|c|c|c|c|}
\hline Plutonium species & $\mathrm{D}$ in $\mathrm{mL} / \mathrm{g}$ & $\begin{array}{l}\text { Literature values } \\
\text { range and } \\
\text { radionuclide } \\
\text { calculated from } \\
{[28]^{*}}\end{array}$ & Conditions \\
\hline $\mathrm{Pu}(\mathrm{III})$ & $71 \pm 11$ & $10^{4}$ to $10^{5}(\mathrm{Am}(\mathrm{III}))$ & $\begin{array}{l}1.0 \mathrm{M} \mathrm{HNO}_{3}, 1.0 \mathrm{M} \\
\mathrm{HCl}\end{array}$ \\
\hline $\mathrm{Pu}(\mathrm{IV})$ & $153 \pm 17$ & $10^{5}$ to $10^{6}(\mathrm{Pu}(\mathrm{IV}))$ & $\begin{array}{l}1.0 \mathrm{M} \mathrm{HNO}_{3}, 1.0 \mathrm{M} \\
\mathrm{HCl}\end{array}$ \\
\hline $\mathrm{Pu}(\mathrm{V})$ & $3.4 \pm 9$ & - & \\
\hline $\mathrm{Pu}(\mathrm{VI})$ & $3.7 \pm 7$ & $10^{5}$ to $10^{6}(\mathrm{U}(\mathrm{VI}))$ & $\mathrm{pH}=6.4, \mathrm{pH}=2$ \\
\hline Colloidal Pu(IV) & $3.5 \pm 5$ & - & $\mathrm{pH}=4.30$ \\
\hline $\mathrm{U}(\mathrm{VI})$ & $1.6 \pm 5$ & $10^{5}$ to $10^{6}(\mathrm{U}(\mathrm{VI}))$ & $\mathrm{pH}=6.4$ \\
\hline
\end{tabular}

"Values were calculated by dividing k' values from the paper by 1.98 to express the same distribution factor as in our studies See reference [28]. 
Figure

Draft 7

$1 \quad$ 8.0 Figures.

2 Figure 1.

3

4

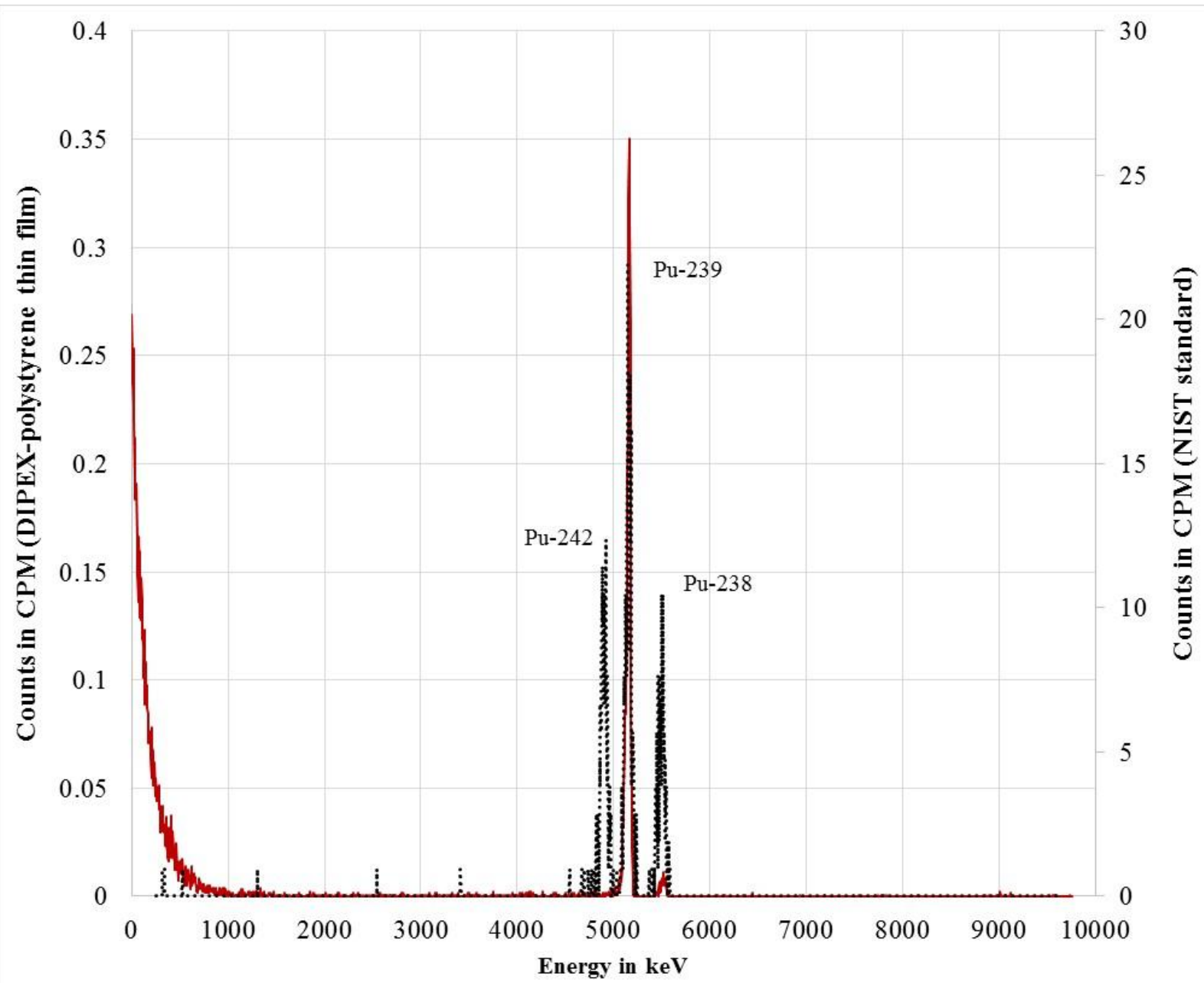

5

6

7

8

9

10 
Draft 7

12 Figure 2.

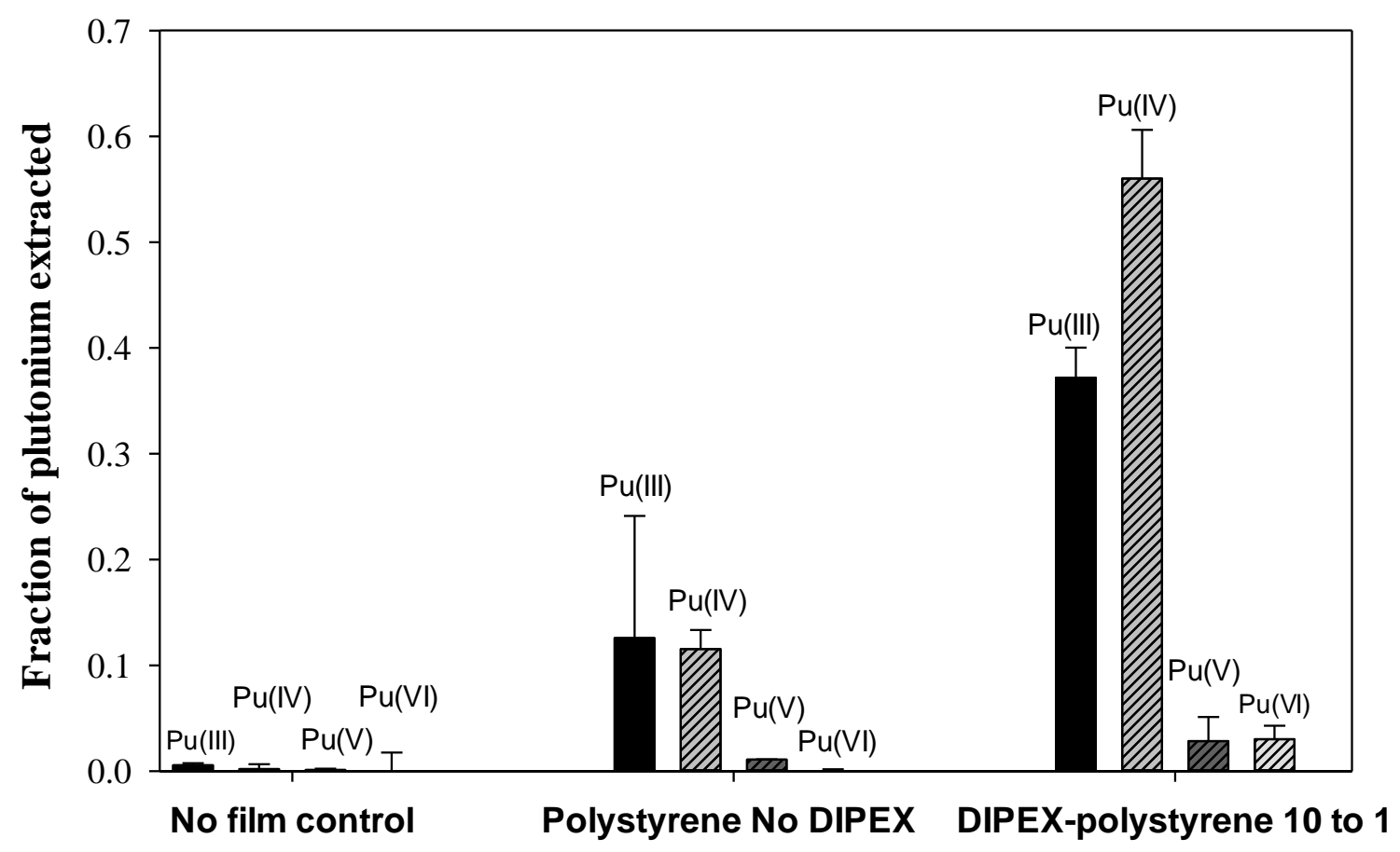

13

14

15

16

17

18

19

20

21

22

23 


\section{Draft 7}

Figure 3.

26

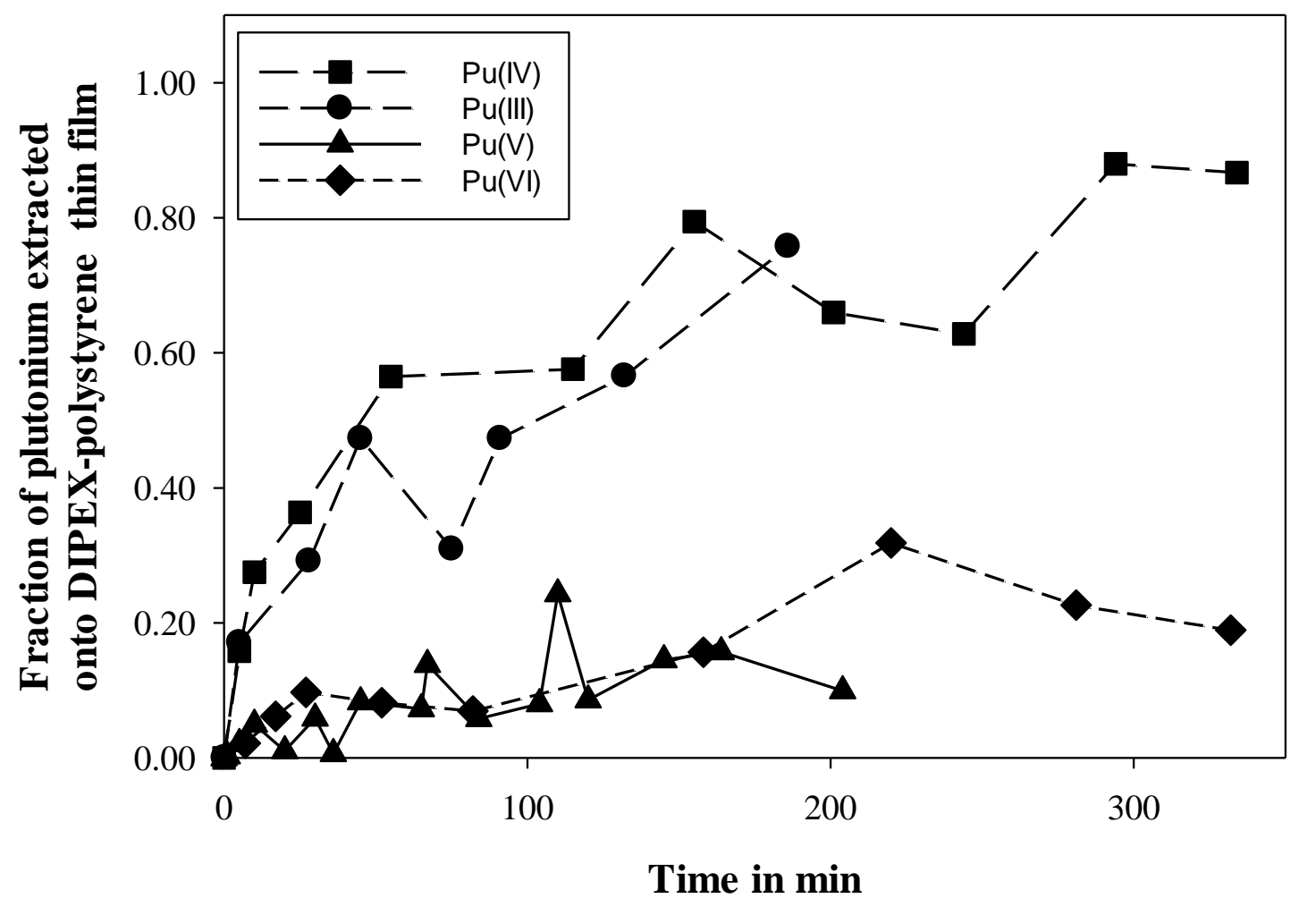




\section{Draft 7}

\section{$37 \quad$ Figure 4.}

38

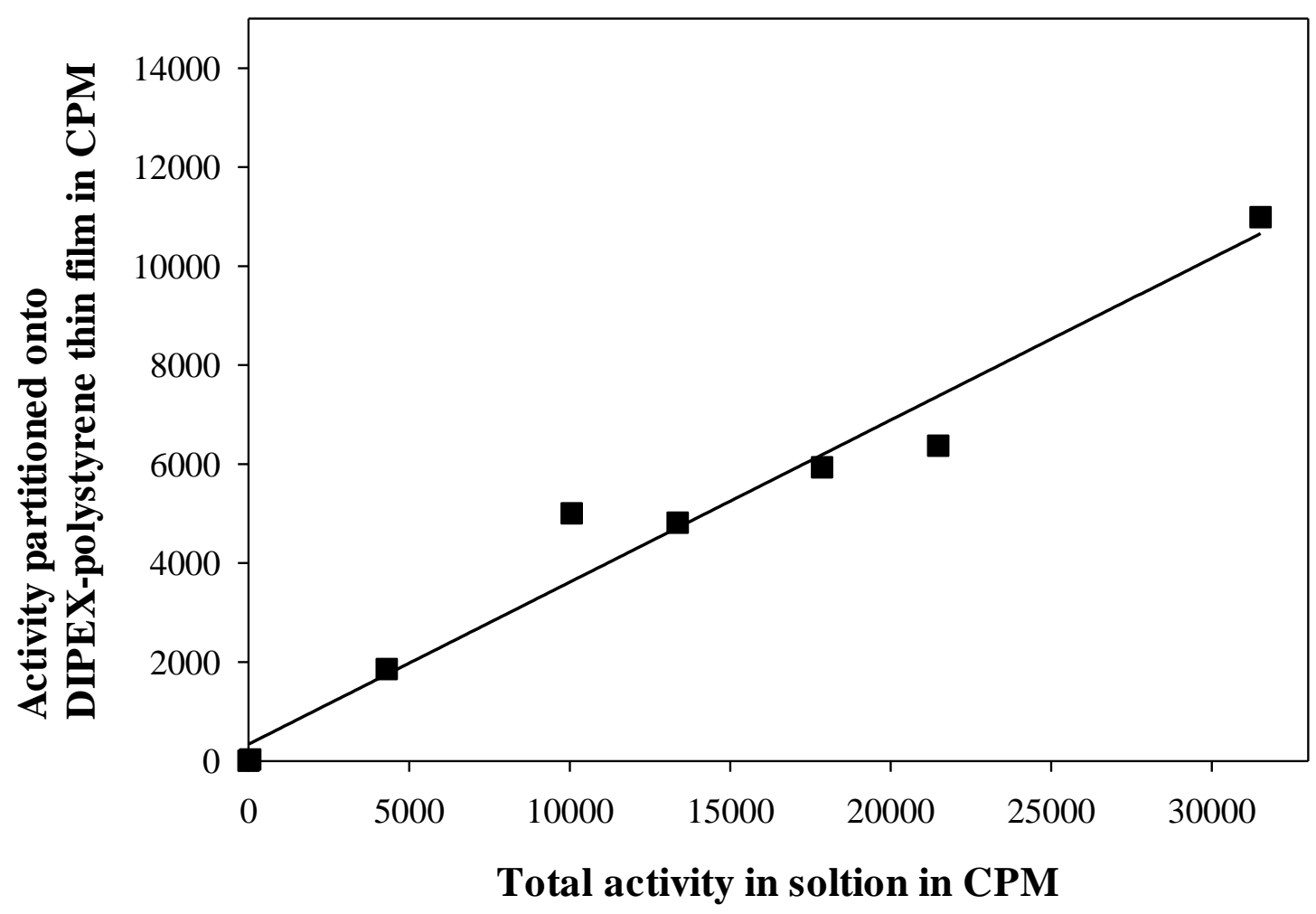

40

41

42

43

44

45

46

47

48 
Draft 7

Figure 5.
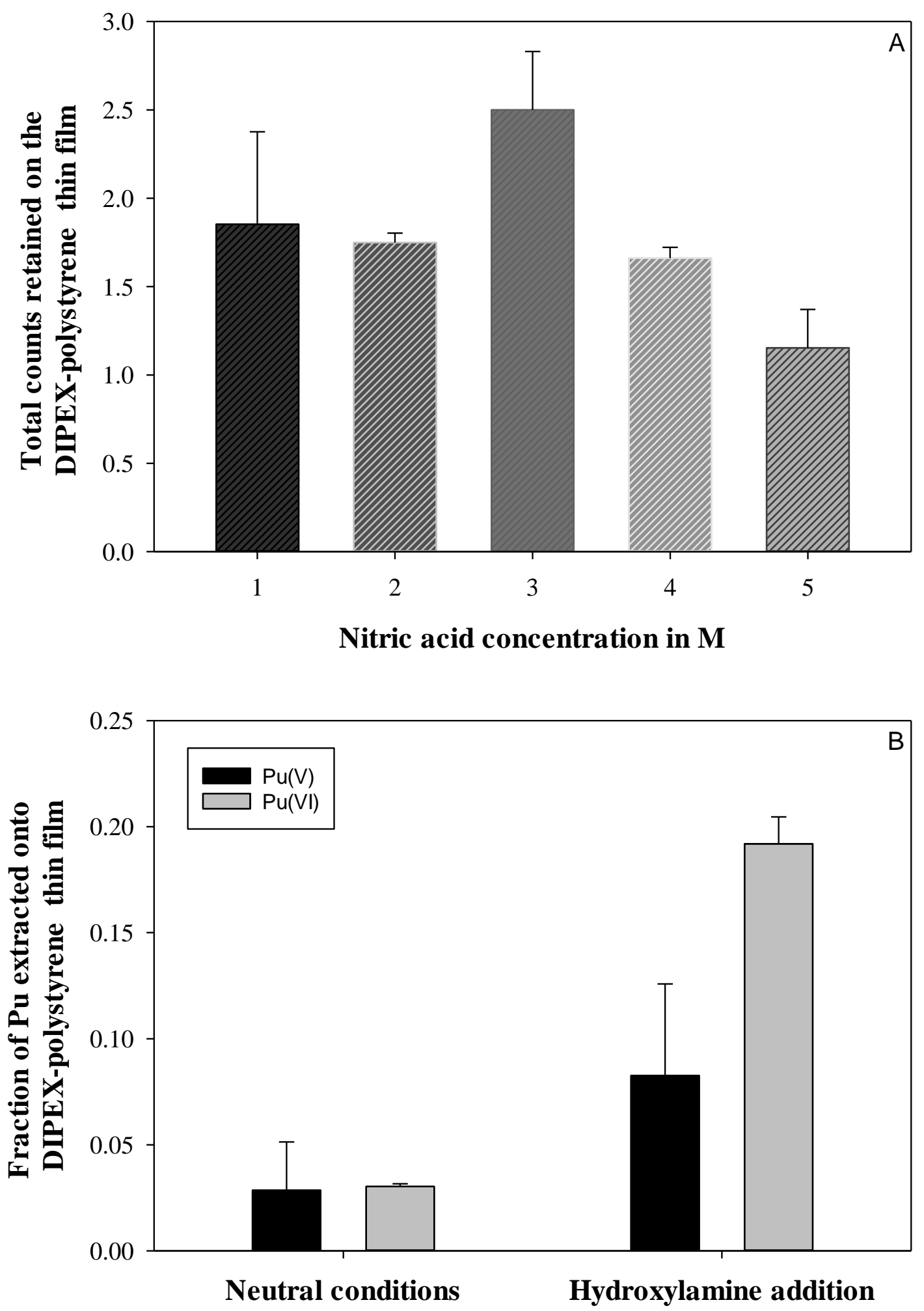
Draft 7

51

$52 \quad$ Figure 6.

53

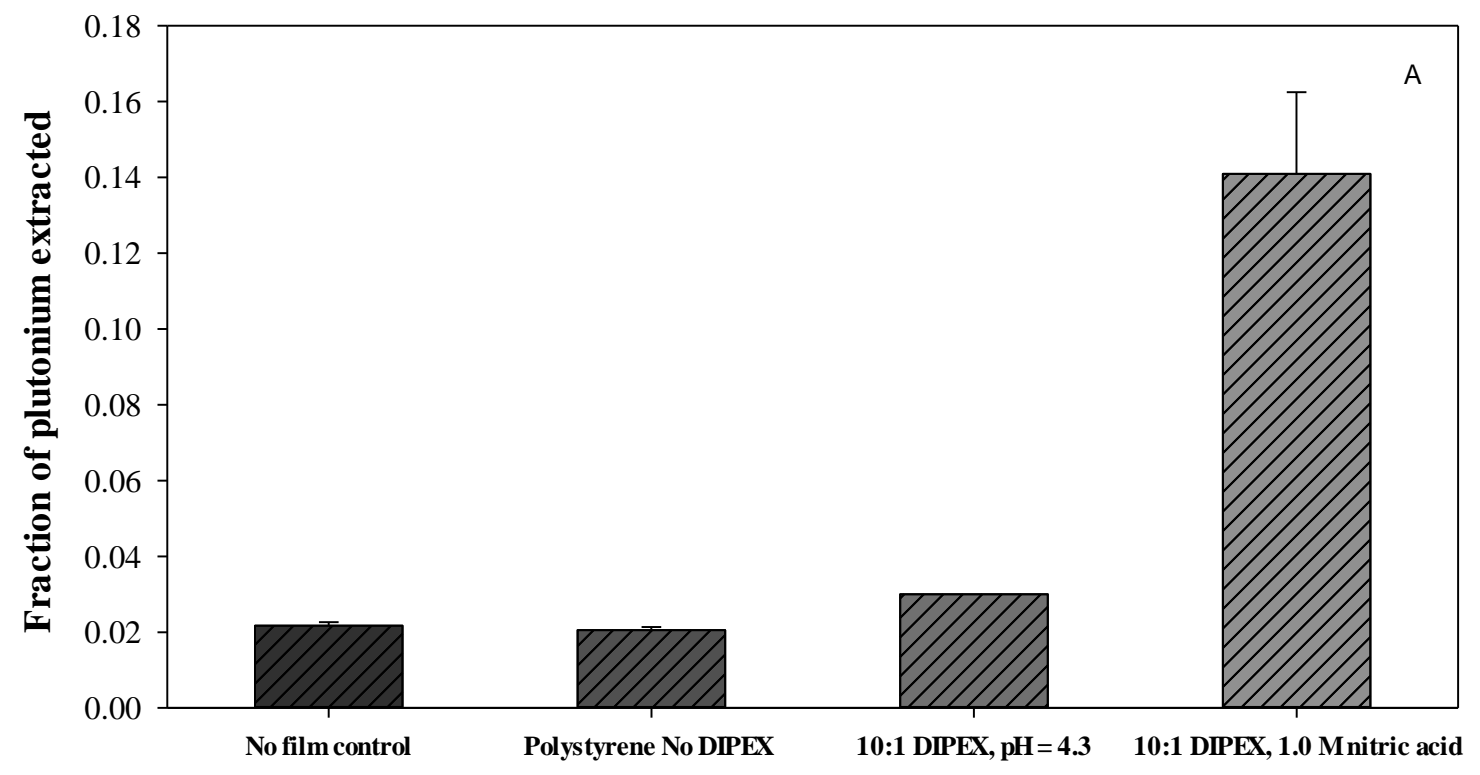

54

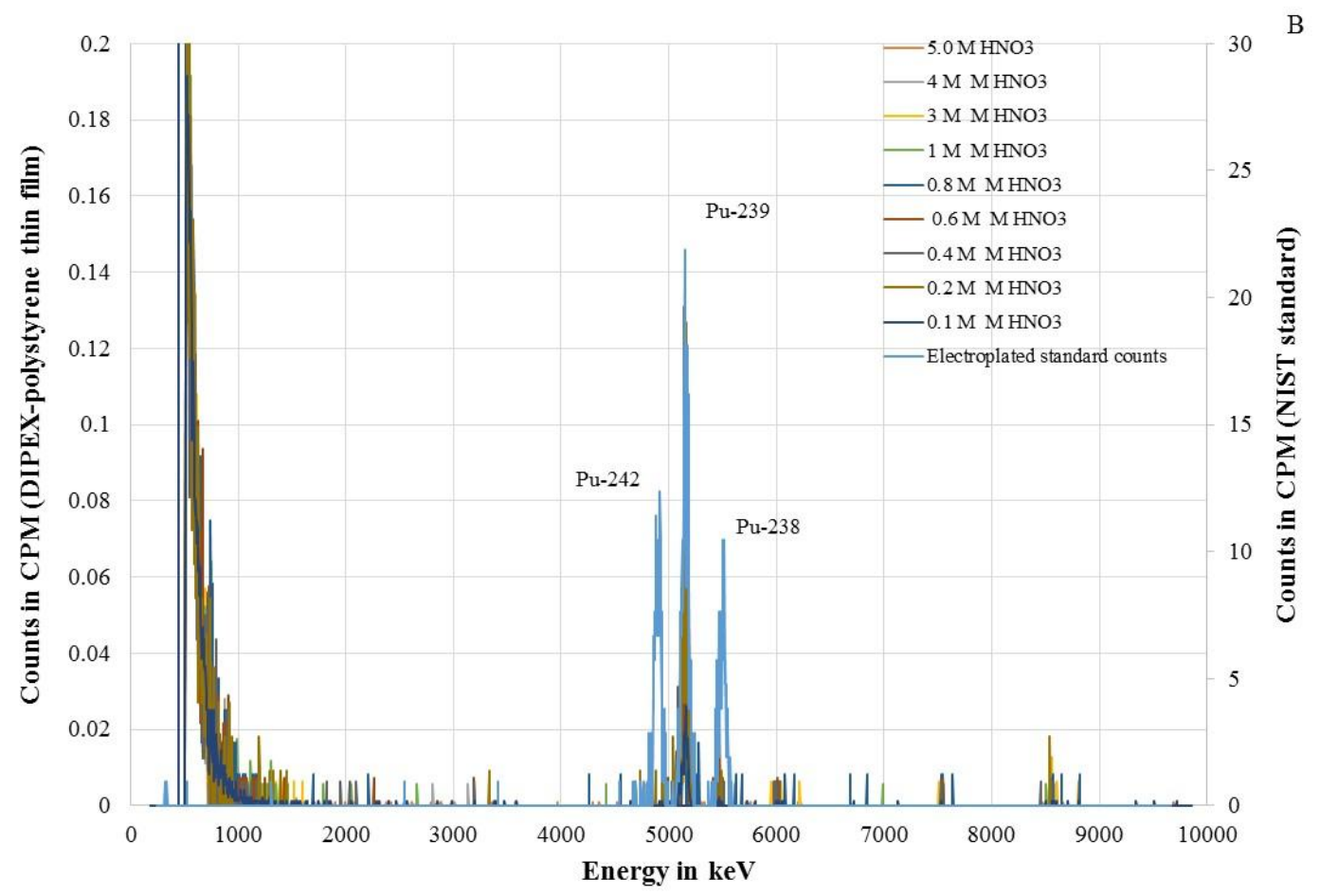




\section{Draft 7}

\section{$56 \quad$ Figure 7.}

57

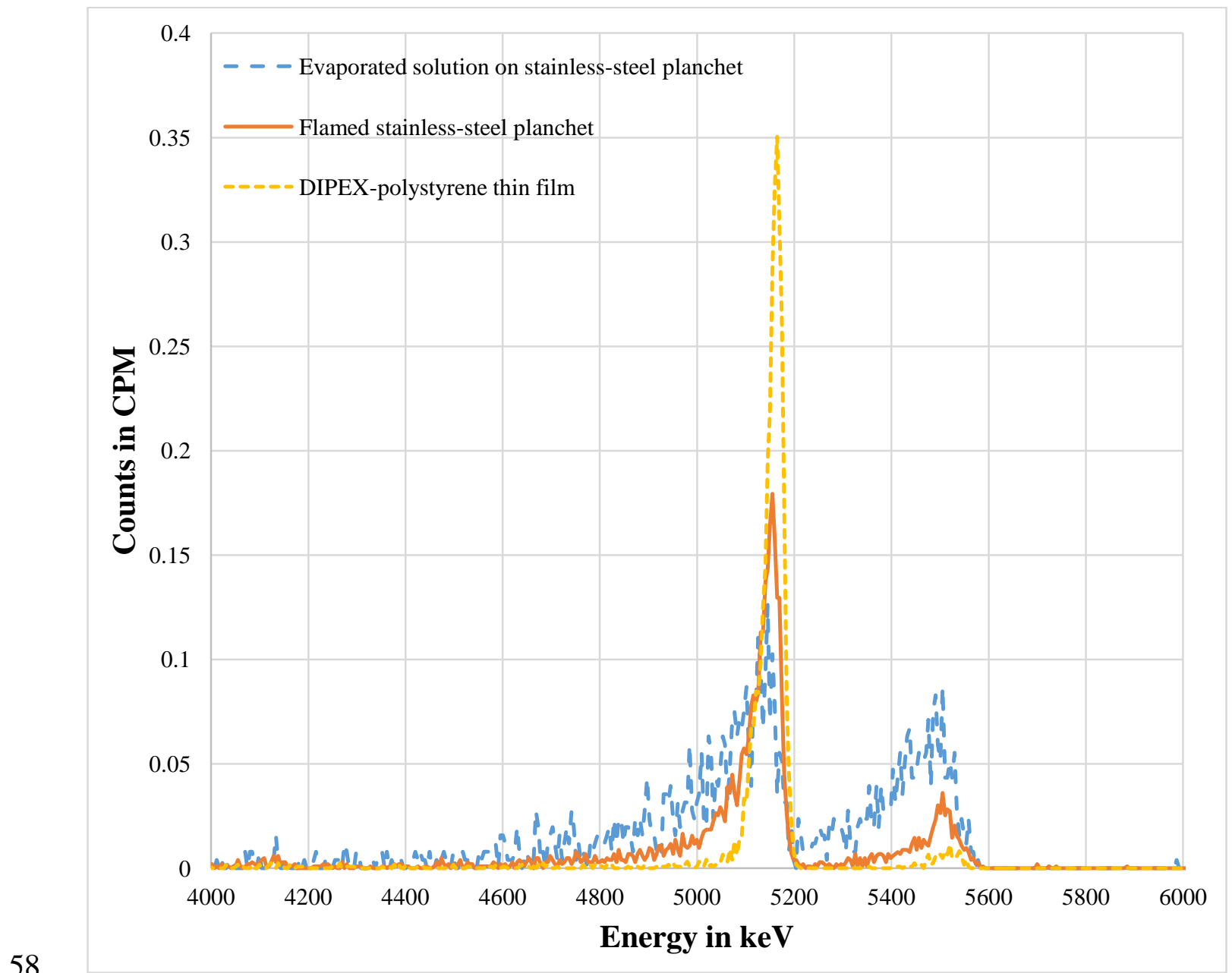

59

60 